\title{
Perancangan DC Cooler Berbasis Internet of Things
}

\author{
Haris Isyanto ${ }^{1}$, Adhimukti Nandiwardhana ${ }^{2}$ \\ 1) 2) Teknik Elektro Universitas Muhammadiyah Jakarta \\ Jl. Cempaka Putih Tengah 27 No 47 \\ Email: ${ }^{1)}$ haris.isyanto@ftumj.ac.id, 2) 2014420002@ftumj.ac.id
}

\begin{abstract}
ABSTRAK
Pada era globalisasi yang semakin berkembang secara pesat dari berbagai teknologi, semakin banyak perangkat yang sudah dapat mengakses internet. Bahkan internet pun sudah menjadi kebutuhan manusia dalam melakukan hal berbagai kegiatan. Kini internet sudah dapat diakses dengan mudah dan dapat diintegrasikan dengan peranti seperti, komputer, smartphone. Melalu jaringan global semua dapat diakses dengan mudah dan cepat. Namun pada industri telekomunikasi terutama BTS menggunakan Baterai sebagai sumber tegangan cadangan apabila terjadi pemadaman listrik oleh PLN. Baterai yang digunakan sangat rentan dengan kenaikan suhu yang mengakibatkan umur baterai yang rendah. Untuk mengurangi hal tersebut dengan membuat sebuah Dc cooler yang dapat mengurangi dampak dari kerusakan baterai tersebut. Serta dengan sistem yang berbassi Internet of Things maka dalam memonitoring keadaan baterai akan menjadi lebih mudah. Dalam perancangan Dc cooler Berbasis Internet Of thungsmenggunakan sebuah sensor yang dapat membaca suhu dan kelembapan dari baterai tersebut. Sehingga operator dapat lebih mudah mendeteksi adanya kerusakan atau kelaianan dalam BTS dengan menggunakan aplikasi perangkat lunak yaitu Blynk. Hasil dari perancangan ini menghasilkan sebuah alat yang akan dipasang pada system Dc cooler tersebut yaitu Sensor DHT22, SIM800L, Buzzer, dan Relay untuk Dc cooler. Dalam sistem ini pengguna dapat memonitoring suhu beserta kelembapan melalui handphone pada aplikasi perangkat lunak yaitu blynk yang terintegerasi dengan sensor. Sistem berkomunikasi dengan seluruh komponen yaitu sensor DHT22, SIM800L, buzzer, relay yang dikonfigurasikan oleh ESP8266 NodeMcu serta Arduino agar dapat terhubung pada jaringan internet. Sistem ini harus selalu terhubung pada intenet agar dapat memonitoring secara berkala. Dengan menggunakan Dc cooler sebagai pendingin maka baterai akan tetap beerada pada suhu yang stabil dan tidak mengurangi umur baterai
\end{abstract}

kata kunci : dc cooler, dht22, relay, buzzer, sim8001, esp8266, arduino, internt of things

\section{PENDAHULUAN}

Pada era globalisasi yang semakin berkembang secara pesat dari berbagai teknologi, semakin banyak perangkat yang sudah dapat mengakses internet. Divais yang kita pakai saat ini bisa dimonitor secara mudah dan dikontrol dari jarak yang berbeda seperti oleh ponsel pintar dan tablet[1]. Bahkan internet pun sudah menjadi kebutuhan manusia dalam melakukan hal berbagai kegiatan [2]. Kini internet sudah dapat diakses dengan mudah dan dapat diintegrasikan dengan peranti seperti, komputer, smartphone. Melalu jaringan global semua dapat diakses dengan mudah dan cepat. Semua interaksi yang kita lakukan dengan bantuan internet bisa disebut Internet of Things (IOT). Internet of thing menjadi sebuah bidang penelitian tersendiri semenjak berkembangnya teknologi internet dan media komunikasi lain [3]. Belakangan ini, mikrokontroler keluarga Arduino menjadi sangat populer [4]. Rumah merupakan salah satu kebutuhan pokok dalam kehidupan manusia [5]. Didalam sistem jaringan distribusi listrik lokal (local grid) yang kita mengenal istilah microgrid dan nanogrid yang terkenal untuk pembangkit listrik yang berdiri sendiri [6].
Perkembangan teknologi mendorong sektor industri untuk lebih kreatif dalam membuat sebuah alat sederhana yang dapat membantu masyarakat dalam kehidupan sehari-hari sehingga dapat berguna bagi banyak orang dan berfungsi baik [7]. Rangkaian band pass filter adalah rangkaian yang mengizinkan lewat sinyal yang memiliki frekuensi pada rentang tertentu dan mengattenuasikan sinyal yang memiliki frekuensi di luar rentang tersebut [8]. Untuk dapat mendayai suatu beban listrik dengan baik, dalam hal ini merupakan rumah kaca, diperlukan desain sistem yang baik pula [9]. Salah satu bahan semikonduktor organik yang sering digunakan adalah pentacene karena ketersediaannya dan kinerja divaisnya [10]. Dihunian yang modern saat ini, tak sedikit pula rumah yang memiliki kamera cctv untuk mendukung keamanan rumahnya [11] .Operasi pembangkit tenaga listrik harus aman dan terpercaya [12]. Intensitas radiasi cahaya matahari yang diterima sel surya sebanding dengan tegangan dan arus listrik yang dihasilkan oleh sel surya [13]. Energi listrik merupakan salah satu kebutuhan pokok yang sangat penting dalam kehidupan manusia saat ini, hampir semua aktifitas manusia berhubungan dengan energi 
listrik [14]. Transistor efek medan berbasis semikonduktor organik bisa dimanfaatkan untuk sensor kelembaban [15]. Penggunaan kapasitor bank di industri misalnya sebagai alat kompensator faktor daya, memperbaiki drop tegangan pada ujung jaringan, atau kenaikan suhu dan arus pada penghantar bisa diperkecil dengan di pasang kapasitor [16]. Mengerjakan proyek tepat waktu sesuai dengan biaya, lingkup pekerjaan, serta mutu yang sudah ditetapkan menjadi target setiap perusahaan [17]. Perkembangan dibidang ilmu pengetahuan dan teknologi memiliki kemajuan yang sangat pesat yang berdampak pada kehidupan kita saat ini [18]. Energi menjadi salah satu isu yang dihadapi oleh Indonesia saat ini bahkan dunia, karena ketidakseimbangan antara ketersediaan energi dengan kebutuhanya [19]. Energi sangat penting untuk manusia untuk bisa bertahan hidup [20]. Arduino berfungsi membaca nilai pada sensor tegangan AC, sensor tegangan DC, LCD [21]. Pengukuran adalah suatu pembandingan antara suatu besaran dengan besaran lain yang sejenis secara eksperimen dan salah satu besaran dianggap sebagai standar [22]. Rangkaian penyearah gelombang penuh adalah penyearah yang mengonversikan kedua siklus positif dan negative dari sinyal AC menjadi sinyal DC yang berdenyut [23]. PLTH ini dioperasikan untuk memikul beban [24].Perangkat yang merupakan bagian dari jaringan nirkabel disebut " objek pintar " atau " hal-hal pintar ", yang tidak seperti perangkat yang normal dapat berinteraksi dalam sistem komunikasi di mana mereka dimasukkan karena mereka memiliki peran aktif satu dengan lainnya [25]. Dengan adanya Internet of Things dapat memudahkan pengguna saat mengakses atau menggunakan piranti yang berada pada jarak jauh secara Real Time. Pada industri telekomunikasi terutama BTS menggunakan Baterai sebagai sumber tegangan cadangan apabila terjadi pemadaman listrik oleh PLN. PENDAHULUAN

Pada Base Transceiver Station (BTS) masalah pendinginan baterai dan perangkat telekomunikasi sangat penting [26]. Baterai yang digunakan sangat rentan dengan kenaikan suhu yang mengakibatkan umur baterai yang rendah. Kini sudah ada DC COOLER sebagai pendingin baterai yang menjaga suhu baterai tetap pada suhu idealnya. Monitoring suhu baterai pada BTS sangat penting sekali, agar menjaga kondisi baterai dan perangkat DC COOLER akan tahan lama. Dengan berkembangnya teknologi seperti mikrokontroler akan memudahkan dalam mengontrol piranti dengan memrogram kedalam mikrokontroler tersebut.

\section{METODOLOGI}

\section{FLOWCHART SISTEM DC COOLER BERBASIS IOT}

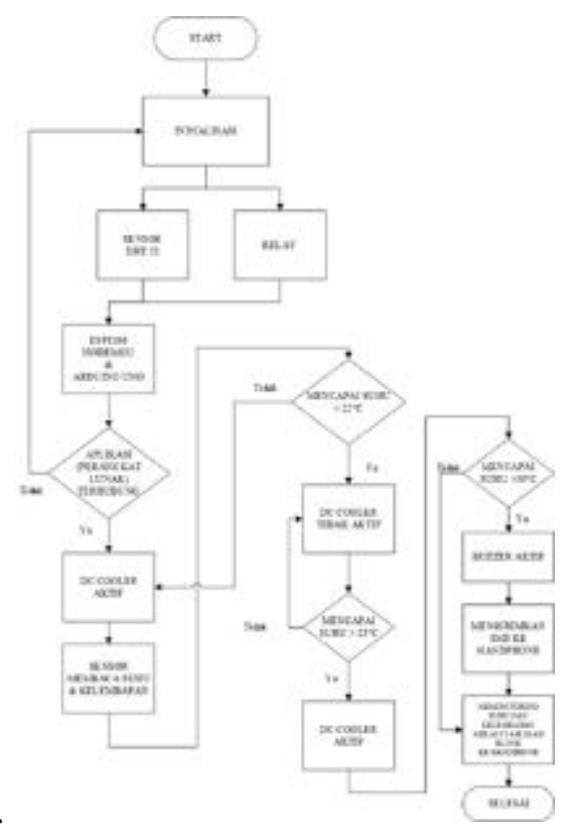

Gambar 1 Flowchart sistem Dc cooler Berbasis IoT.

Fungsi flowchart ini sebagai sistem Dc cooler berbasis IOT. Sistem ini bekerja apabila semua input seperti, sensor, dan ESP8266 NodeMcu terhubung agar berkomunikasi dengan sensor serta ESP8266 NodeMCu. Sistem ini mengatifkan relay agar menggerakan Dc cooler saat sensor membaca batas suhu yang sudah ditetapkan lalu mengnonaktifkan Dc cooler apabila sensor membaca suhu yang telah ditetapkan juga. Relay akan mengaktifkan Dc cooler sebelum mencapai suhu yang telah ditetapkan. Setelah itu sensor membaca suhu dan kelembaban lalu memberikan data tersebut ke Handphone melalui aplikasi perangkat lunak yang telah disediakan. Ketika sensor mendekteksi adanya kenaikan suhu yang tinggi maka buzzer akan berbunyi dan mengirimkan notifikasi via SMS ke Handphone. Siklus pada sistem ini bekerja secara berurutan.

\section{BLOK DIAGRAM}

Maksud dari Blok diagram Dc cooler ini yaitu sebuah Handphone dapat memonitoring Dc cooler melalui internet dengan sebuah aplikasi perangkat lunak yang digunakan. Internet ini berfungsi sebagai jalur komunikasi antara aplikasi perangkat lunak dan ESP8266 NodeMcu, dengan menggunakan module Wi-Fi yang sudah disediakan oleh ESP8266 NodeMcu. Internet harus selalu terhubung agar sistem Dc cooler terus berjalan. Selain dengan menggunakan internet. Dc cooler juga mempunyai Modul GSM yang terdiri dari modul SIM800L v2 yang berfungsi untuk memberikan notifikasi kepada 
RESISTOR (Elektronika Kendali Telekomunikasi Tenaga Listrik Komputer) Vol. 2 No. 2 e-ISSN : 2621-9700, p-ISSN : 2654-2684

pengguna dengan menggunakan SMS apabila suhu yang dibaca oleh sensor DHT22 mengalami kenaikan suhu yang tinggi. Sistem ini bekerja sebagai memonitoring suhu selama terus menerus lalu data yang diberikan akan langsung terhubung pada SIM800L v2 dan ESP8266 NodeMcu. DHT22 berisi komponen yang telah terkalibrasi secara digital untuk sensor suhu dan kelembaban [27]. Peltier Cooler merupakan modul yang dapat menyerap panas menjadi dingin dengan menggunakan efek peltier sebagai dasar dari prinsip kerjanya [28].

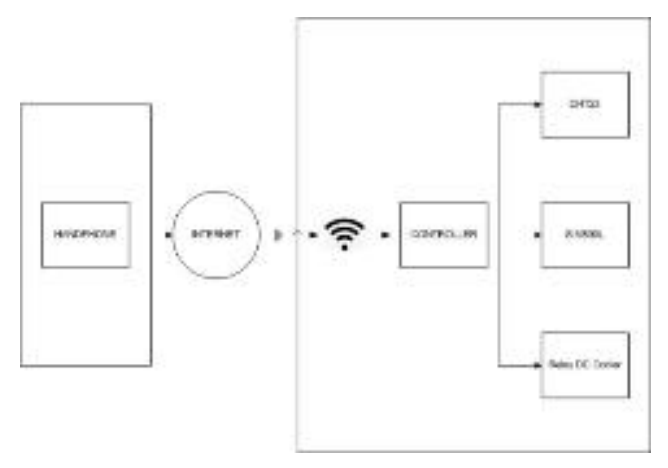

Gambar 2 Diagram blok.

\section{FLOWCHART PERANGKAT LUNAK}

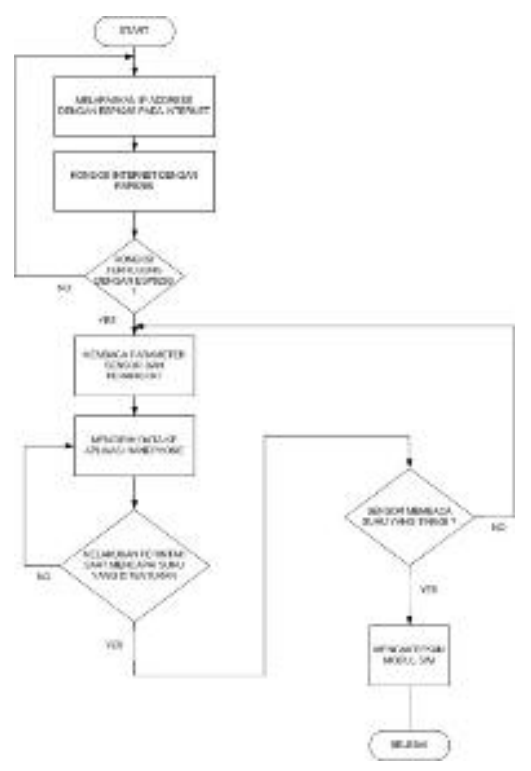

Gambar 3 Flowchart perangkat lunak.

Fungsi flowchart perangkat lunak sebagai komunikasi antara Arduino, SIM800l, sensor tersebut. Media internet sangat penting untuk menghubungkan Arduino pada aplikasi perangkat lunak yang digunakan. Sedangkan SIM800L tersebut sebagai komunikasi antara pengguna untuk komunikasi secara wireless. Dengan menggunakan
ESP8266 NodeMcu Dc cooler ini dapat bekerja secara wireless. Fungsi internet tersebut agar dapat memonitoring melalui handphone dengan jarak dekat maupun jauh. Lalu sensor tersebut juga berfungsi sebagai pemicu aktifnya atau nonaktifnya alat ini. sensor akan bekerja setelah terhubung internet serta terhubung pada aplikasi perangkat lunak yang digunakan

\section{HASIL DAN PEMBAHASAN}

- PENGUJIAN DAN ANALISA

Hasil Pada bab pengujian dan analisa ini dilakukan supaya dapat mengetahui apakah alat yang dirancang bekerja sesuai dengan alat yang diharapkan atau tidak atau tidak. Pengujian dilakukan pada perangkat keras dan perangkat lunak.

\section{- PENGUJIAN SISTEM BLYNK}

Dalam pengujian menggunakan sistem blynk ini, pengguna harus memiliki kode authentic tokens agar mendapatkan akses dalam blynk ini. jadi user dapat menggunakan aplikasi perangkat lunak blynk. Setelah itu user dapat memilih widget yang dinginkan dalam memonitoring alat ini. dalam pengujian ini menggunakan widget superchart dan gauge.

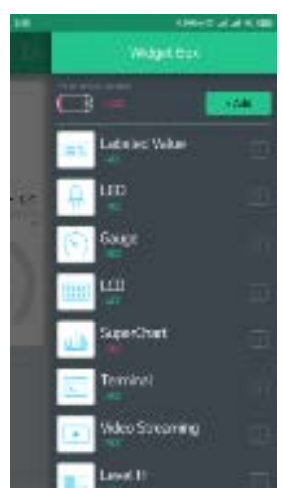

Gambar 4 Tampilan widget box pada blynk.

\section{- MONITORING SENSOR APLIKASI BLYNK}

Pada pengujian aplikasi perangkat lunak dalam monitoring sensor yang digunakan menunnjukan hasil dari sensor yang bekejra berupa menampilkan sebuah grafik dari sensor DHT22 berupa pengukuran suhu serta kelembaban ruangan. Berikut adalah tampilan aplikasi perangkat lunak monitoring sensor : 
RESISTOR (Elektronika Kendali Telekomunikasi Tenaga Listrik Komputer) Vol. 2 No. 2 e-ISSN : 2621-9700, p-ISSN : 2654-2684

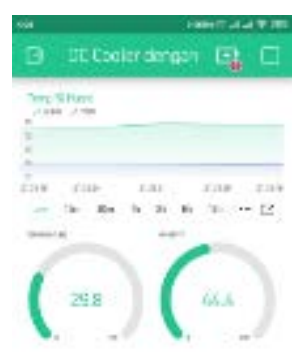

Gambar 5 Monitoring sensor pada aplikasi blynk.

Dalam pengambilan data yang diambil oleh aplikasi blynk dapat diakses dengan cara membuka aplikasi blynk lalu membuka widget superchart lalu akan ada fitur export to CSV yang bisa dibuka melalui Microsoft excel

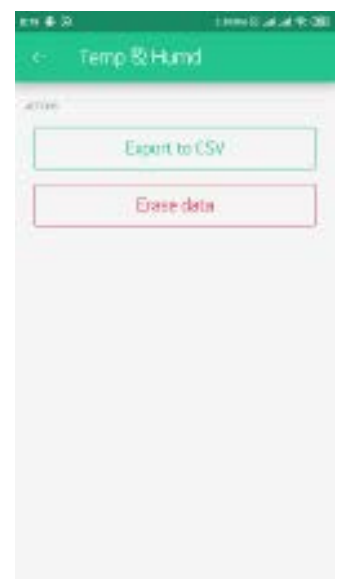

Gambar 6 Fitur pengambilan data dari aplikasi blynk.

\section{- PENGUJIAN DC COOLER}

Pada pengujian Dc cooler ini untuk mengukur apakah alat ini bekerja sesuai dengan parameter yang di tentukan. Sebelumnya akan dilakukan pengujian alat ini dengan mengukur kemampuan dari Dc cooler ini dalam mendinginkan ruang tersebut berikut dibawah gambar dan tabel pengujian Dc cooler :

Tabel 1 Pengujian Dc cooler.

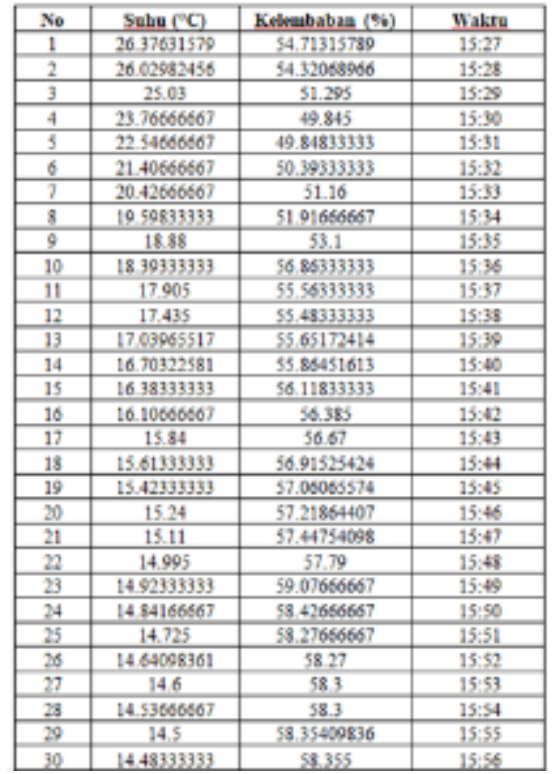

\begin{tabular}{|c|c|c|c|}
\hline 31 & 14.41666667 & 58.3 & $15: 57$ \\
\hline 32 & 14.35333333 & 58.32372581 & $15: 58$ \\
\hline 33 & 14,29833333 & 58.42622951 & $15: 59$ \\
\hline 34 & 14.23333333 & 58.49 & $16: 80$ \\
\hline 35 & 142 & 58.59333333 & 1601 \\
\hline 36 & 14.2 & 58.63858305 & $16: 02$ \\
\hline 37 & 14.15166667 & 58.7295082 & 16.03 \\
\hline 38 & $14.1416666 ?$ & 58.83656667 & 16.04 \\
\hline 39 & 14.13666667 & 58.87656667 & 1605 \\
\hline 40 & 14.16333333 & 58.85932203 & 16.06 \\
\hline 41 & 14.10656667 & 58.79836006 & 1607 \\
\hline 42 & 141 & 5873 & 1608 \\
\hline 43 & 14.09 & 58.08322034 & $16: 29$ \\
\hline 44 & 1401 & 58.623333333 & $16: 10$ \\
\hline 45 & 14 & 38.60527506 & $16: 11$ \\
\hline 46 & 14 & $\$ 8.60333333$ & $16: 12$ \\
\hline 47 & $13.9416666 ?$ & 58.6 & $16: 13$ \\
\hline 48 & 13.90335333 & 58.60538583 & 16:14 \\
\hline 49 & 13.9 & 53.60327869 & $16: 15$ \\
\hline 50 & 13.85333333 & 58.59 & $16: 16$ \\
\hline 51 & 13,33 & 59.555 & $16: 17$ \\
\hline 52 & 13.8 & 58.5779661 & $16: 18$ \\
\hline 53 & 13.8 & 58.59658525 & 16.19 \\
\hline 54 & 13.8 & $58.64+46678$ & 1620 \\
\hline 55 & 13.76656567 & 58.71 & $16: 21$ \\
\hline 56 & 13.72 & 58.02333333 & 1622 \\
\hline 57 & 13.765 & 58.87 & 10.23 \\
\hline 58 & 13.79833333 & 589 & 16.24 \\
\hline 59 & 13.79535333 & 58.89444262 & 16.25 \\
\hline 60 & 13.79333333 & 58.89983051 & 1626 \\
\hline
\end{tabular}

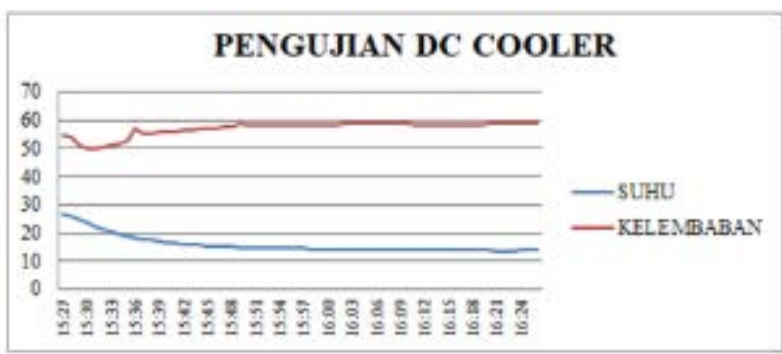

Gambar 7 Grafik pengujian Dc cooler.

Dari tabel pengamatan diatas menunjukan bahwa Dc cooler akan terus bekerja mendinginkan ruangan hingga serendah mungkin. Dalam waktu 60 menit Dc cooler ini mendinginkan ruang hingga $13^{\circ} \mathrm{C}$. tetapi Dc cooler dalam mendinginkan ruang tergantung dari benda yang didalamnya, apabila benda didalamnya memiliki suhu yang lebih rendah 
RESISTOR (Elektronika Kendali Telekomunikasi Tenaga Listrik Komputer) Vol. 2 No. 2 e-ISSN : 2621-9700, p-ISSN : 2654-2684

maka Dc cooler dapat mencapai suhu yang rendah. Pengujian ini dilakukan tanpa ada benda didalamnya.

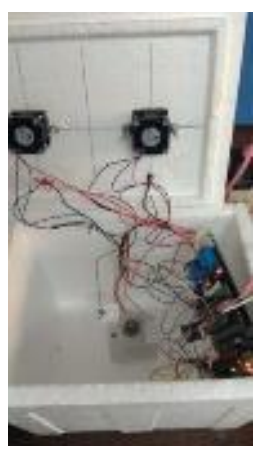

Gambar 8 Pengujian Dc cooler.

- PENGUJIAN DC COOLER TANPA MENGGUNAKAN LAMPU

Dalam pengujian ini Dc cooler akan mendinginkan ruang tanpa adanya lampu sebagai objek yang memiliki sumber panas. Dalam perancangannya alat ini bekerja saat suhu sudah mencapai $>25^{\circ} \mathrm{C}$ Maka relay akan aktif dan pada saat suhu sudah mencapai $<22^{\circ} \mathrm{C}$ maka relay akan non aktif sehingga Dc cooler akan nonaktif. Pengujian ini dilakukan selama 60 menit.

Tabel 2 Pengujian Dc cooler tanpa lampu.

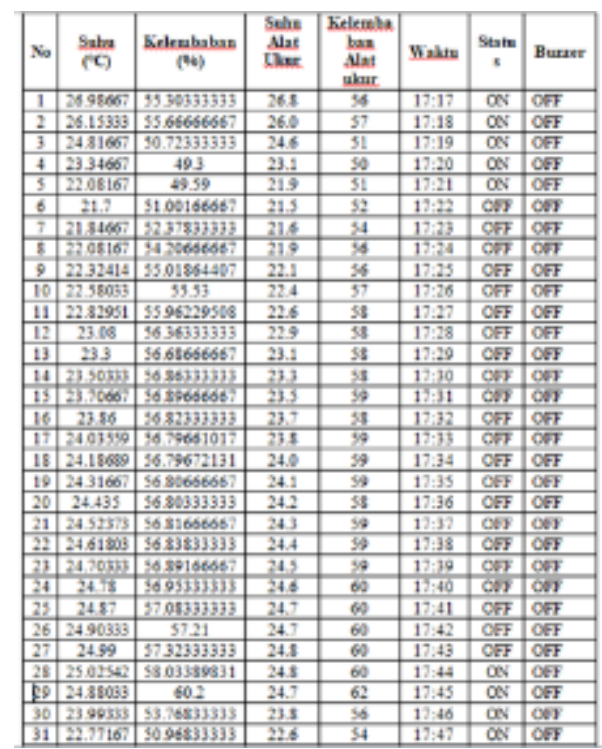

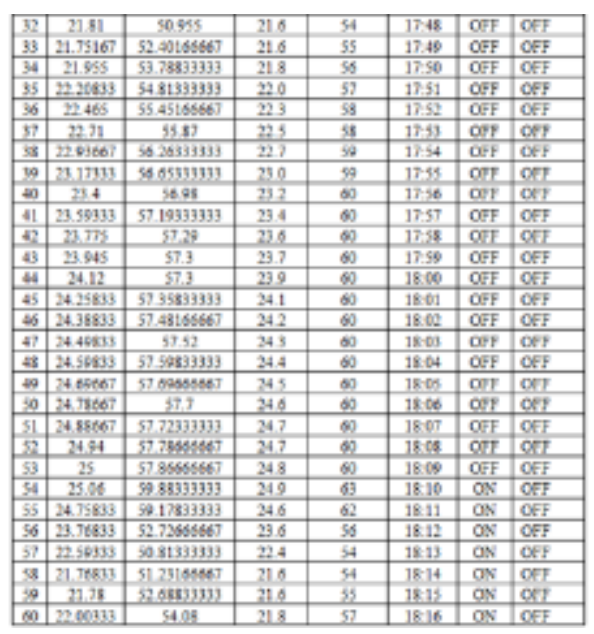

PENGUJAN DC COOLER TANPA LAMPU

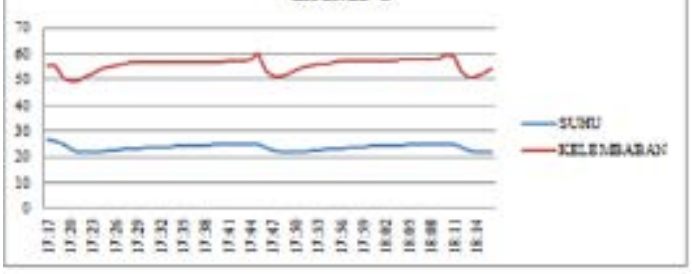

Gambar 9 Grafik pengujian Dc cooler tanpa lampu.

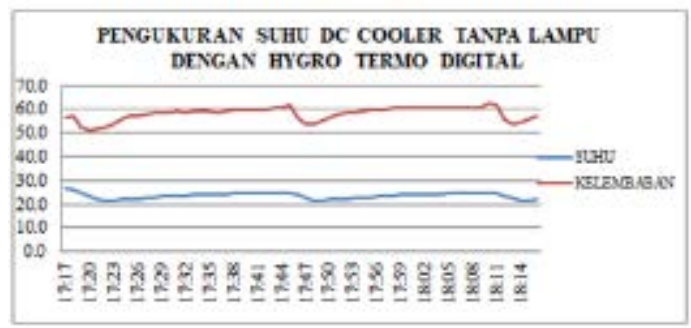

Gambar 10 Grafik pengukuran suhu dc cooler tanpa lampu dengan hygro termo digital.

Menurut Tabel diatas menunjukkan bahwa tanpa adanya pemanas atau sumber panas ruangan akan berada dibawah $25^{\circ} \mathrm{C}$ selama sekitar 2 menit, tetapi saat Dc cooler aktif dan mendinginkan ruangan dalam waktu yang relatif singkat yaitu 3 menit. Dengan pengukuran menggunakan thermometer suhu berada dibawah $25^{\circ} \mathrm{C}$. Namun menurut tabel 4.2 terjadi adanya perbedaan pengukuran suhu yang relatif tidak besar, namun tetap mendekati pengukuran dengan menggunakan sensor DHT22. 
RESISTOR (Elektronika Kendali Telekomunikasi Tenaga Listrik Komputer) Vol. 2 No. 2 e-ISSN : 2621-9700, p-ISSN : 2654-2684

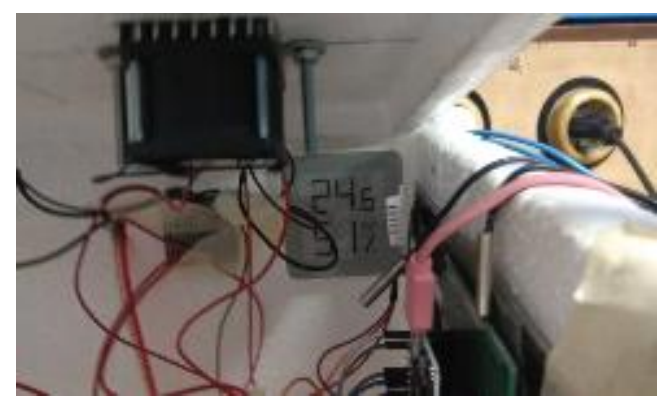

Gambar 11 Pengukuran suhu dc cooler tanpa lampu dengan hygro termo digital.

- PENGUJIAN DC COOLER DENGAN LAMPU 5 WATT

Dengan pengujian ini Dc cooler akan mendinginkan ruang dengan adanya sumber panas yaitu menggunakan lampu bohlam 5 watt, bertujuan sebagai simulasi saat di ruangan tersebut memiliki baterai yang memiliki sumber panas lebih dari suhu normal ruangan

Tabel 3 Pengujian Dc cooler dengan lampu 5 watt.

\begin{tabular}{|c|c|c|c|c|c|c|c|}
\hline So & Sahu $(-C)$ & $\begin{array}{c}\text { Kelembaten } \\
\text { (96) }\end{array}$ & $\begin{array}{l}\text { subse } \\
\text { alat } \\
\text { vikirr }\end{array}$ & $\begin{array}{l}\text { Kelewba } \\
\text { baben } \\
\text { alatukwir }\end{array}$ & Waktu & Status & Buzzen \\
\hline 31 & 25.6 & 43.8 & 25.0 & 42 & 19.22 & $O N$ & OFF \\
\hline 32 & 25.6 & 43.8 & 250 & 42 & 19.23 & $\alpha N$ & OFF \\
\hline 33 & 25.6 & 438 & 250 & 42 & 19.24 & ON & OrF \\
\hline 34 & 25.6147541 & 43.853333333 & 250 & 43 & 19.25 & $\alpha N$ & OFF \\
\hline 35 & 25.66666667 & 43.985 & 25.4 & 44 & 19.26 & $\alpha$ & OFF \\
\hline 36 & 25.7 & 43.85166657 & 252 & 44.5 & 19.27 & $\alpha x$ & OFF \\
\hline 37 & 25,69666667 & 43.745 & 25.1 & 45 & 19.28 & oN & OFF \\
\hline 38 & 25,69666667 & 4367333333 & 251 & 45 & 19.29 & ON & OFF \\
\hline 39 & 25.7 & 43.63 & 25.0 & 45 & 19.30 & oN & OFF \\
\hline 40 & 25.7 & 4362333333 & 255 & 45 & 1931 & ON & OFF \\
\hline 41 & 25.7 & 43.67333333 & 25.5 & 45 & 19.32 & $\alpha$ & OFF \\
\hline 42 & 29.69 & 43.70656667 & 23.5 & 43 & 19.33 & $O N$ & OFF \\
\hline 43 & 25.7 & 43.7 & 255 & 45 & $19-34$ & ON & OFF \\
\hline 44 & 25.7 & 43.62166667 & 25.5 & 45 & 19.35 & $\alpha$ & OFF \\
\hline 45 & 25.7 & 43.53 & 255 & 45 & 19.36 & ON & OFF \\
\hline 46 & 25.7 & 43.50833333 & 25.5 & 49 & $19: 37$ & $\alpha N$ & OEF \\
\hline 47 & \begin{tabular}{|l|l|}
25.70333333 \\
\end{tabular} & 43.496S6S67 & 25.5 & 45 & 19.38 & ON & OFF \\
\hline 48 & 25.7 & \begin{tabular}{|l|l}
48656667 \\
\end{tabular} & 259 & 45 & $19: 39$ & $\alpha N$ & OFF \\
\hline 49 & 25.71 .333333 & 43.5 & 25.5 & 45 & 19.40 & $O N$ & OFF \\
\hline 50 & \begin{tabular}{|l|l|}
25.72666667 \\
\end{tabular} & 43553333333 & 25.5 & 45 & 19.41 & oN & OFF \\
\hline 51 & 25.7960066 & 43.03 & 25.6 & 45 & 19.42 & $O N$ & OEF \\
\hline 52 & 25.34666667 & & 25.6 & 45 & 19.43 & $O N$ & OEF \\
\hline 53 & 25.9 & 43.64 & 25.7 & 45 & 19.44 & $O N$ & OEF \\
\hline 54 & 25.9 & 43.54 & 25.7 & 45 & 19.45 & $O N$ & OFF \\
\hline 55 & 259 & $454433333\}$ & 25.7 & 44 & 19.46 & ON & OF \\
\hline 56 & 25.9 & 43.4 & 25.7 & 44 & 19.47 & ON & OFF \\
\hline 57 & 25.9 & 43.4 & 23.7 & 44 & 19.48 & $O N$ & OFF \\
\hline 58 & 2595853333 & 43.4 & 258 & 44 & 19.49 & $O N$ & OFF \\
\hline 59 & 26 & 43.4 & 25.8 & 44 & 19.90 & $O N$ & OFF \\
\hline 60 & 26.05833333 & 43.4 & 259 & 44 & $19: 51$ & $O N$ & OFF \\
\hline
\end{tabular}
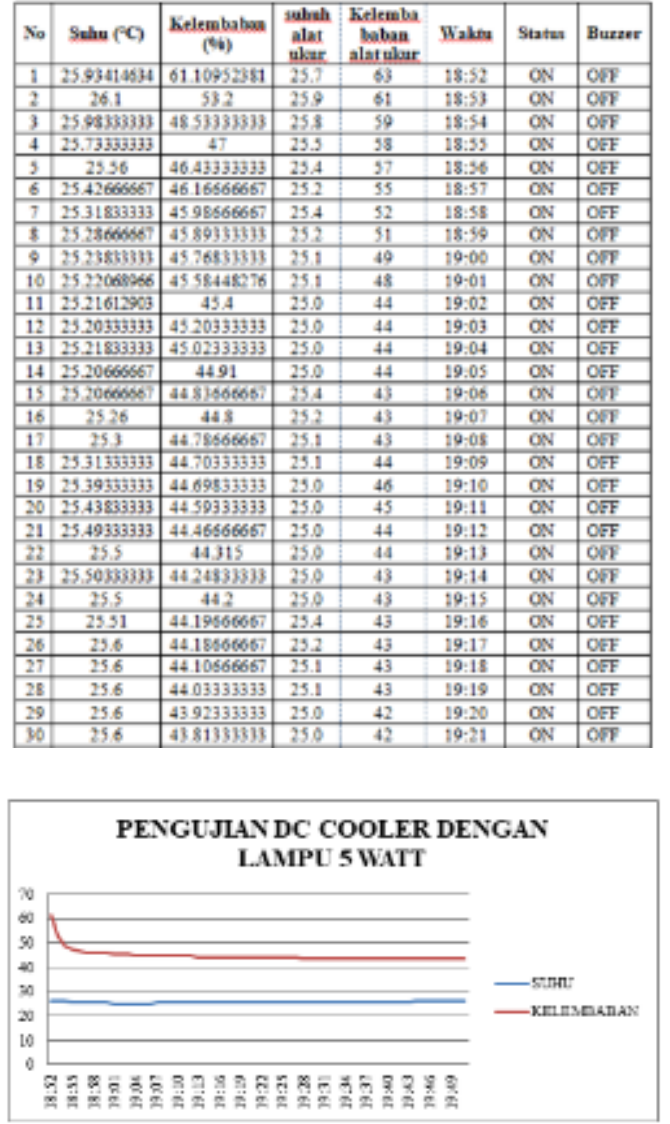

Gambar 12 Pengujian Dc cooler dengan lampu 5 watt.

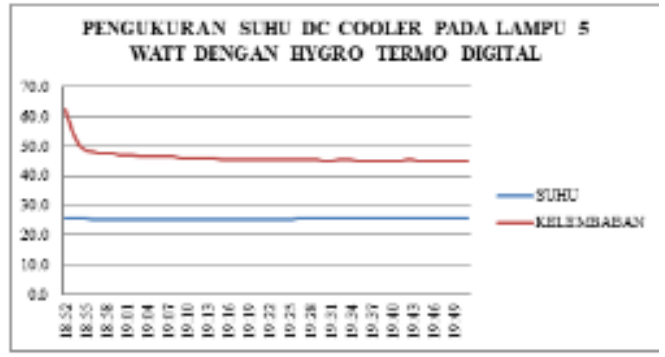

Gambar 13 Pengukuran suhu Dc cooler dengan lampu 5 watt.

Menurut tabel diatas dalam pengujian Dc cooler dengan menggunakan Lampu 5 watt suhu yang dibaca berada pada suhu dengan rata rata $25,61^{\circ} \mathrm{C}$. dan selama 60 menit Dc cooler terus aktif dengan mempertahankan suhu berada di $25^{\circ} \mathrm{C}$. Berikut gambar dibawah ini tampilan pada aplikasi Blymk saat monitoring suhu pengujian Dc cooler dengan lampu 5 watt.

Dengan pengukuran menggunakan hygro termo digital ini didapatkan suhu ruangan pada $25^{\circ} \mathrm{C}$, terjadi perbedaan yang relatif kecil dengan pengukuran menggunakan sensor DHT22. 
RESISTOR (Elektronika Kendali Telekomunikasi Tenaga Listrik Komputer) Vol. 2 No. 2 e-ISSN : 2621-9700, p-ISSN : 2654-2684

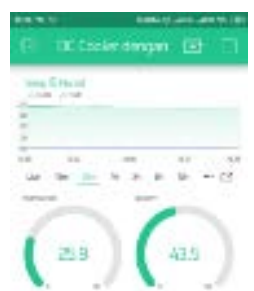

Gambar 14 Monitoring suhu dengan lampu pada aplikasi blynk.

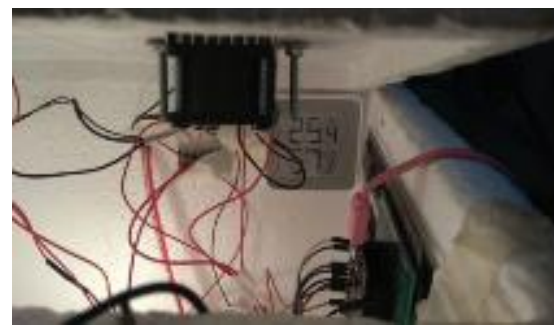

Gambar 15 Pengukuran suhu Dc cooler pada lampu 5 watt dengan hygro termo digital.

\section{- PENGUJIAN DC COOLER DENGAN LAMPU} 15 WATT

Dengan pengujian ini Dc cooler akan mendinginkan ruang dengan adanya sumber panas yaitu menggunakan lampu bohlam 15 watt, bertujuan sebagai simulasi saat di ruangan tersebut memiliki baterai yang memiliki sumber panas yang lebih tinggi

Tabel 4 Pengujian Dc cooler dengan lampu 15 watt.

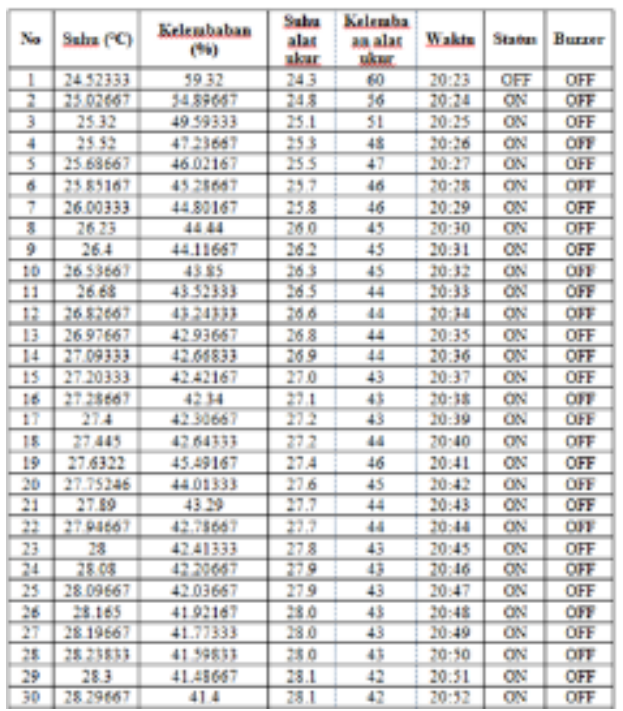

\begin{tabular}{|c|c|c|c|c|c|c|c|}
\hline So & Sube $(-C)$ & $\begin{array}{c}\text { Kolesubabas } \\
\text { (96) }\end{array}$ & $\begin{array}{l}\text { Suhu } \\
\text { alat } \\
\text { whar }\end{array}$ & $\begin{array}{l}\text { Kelemba } \\
\text { ma alat } \\
\text { ukar }\end{array}$ & Wakm & Status & Buzxer \\
\hline 30 & 28.29657 & 41.4 & 28.1 & 42 & 20.52 & ON & OFF \\
\hline 31 & 28.20657 & 41.32167 & 28.1 & 42 & 20.53 & ON & OFF \\
\hline 32 & 28.3 & 41.215 & 28.1 & 42 & 20.54 & $O N$ & OFF \\
\hline 33 & 28.3 & 4119333 & 28.1 & 42 & $20-55$ & ON & OFF \\
\hline 34 & 28.3 & 41.13333 & 28.1 & 43 & $20: 96$ & ON & OFF \\
\hline 35 & 28.3 & 41.1 & 28.1 & 44 & $20: 57$ & $O N$ & OFF \\
\hline 36 & 28.3 & 41.1 & 28.1 & 445 & 20.58 & ON & OF \\
\hline 37 & 28.28657 & 41.1 & 28.1 & 43 & $20: 39$ & ON & OFF \\
\hline 38 & 28.3 & 41.04 & 28.1 & 45 & $21: 00$ & ON & OFF \\
\hline 39 & 28.3 & 41.02667 & 28.1 & 45 & $21: 01$ & ON & OrF \\
\hline 40 & 28.4 & 41 & 28.2 & 47 & 21.02 & ON & OFF \\
\hline 41 & 28.68274 & 4094167 & 28.5 & 45 & 21.03 & ON & OFF \\
\hline 42 & 28.71124 & 40.9 & 28.5 & 45 & $21: 04$ & ON & OFf \\
\hline 43 & 28.91231 & 40.89667 & 28.7 & 44 & 21.05 & ON & OFF \\
\hline 44 & 29.14124 & 40.87167 & 28.9 & 43 & 21.06 & oN & OFF \\
\hline 45 & 29.3877 & 40.81333 & 29.2 & 42 & 21.07 & $O N$ & OFF \\
\hline 46 & 295111 & 40.79333 & 29.3 & 42 & $21: 08$ & ON & OFF \\
\hline 47 & 29.62183 & 40.70333 & 294 & 42 & $21: 09$ & ON & OFF \\
\hline 48 & 29.814 & 42.92 & 29.6 & 44 & $21: 10$ & ON & OFF \\
\hline 49 & 298571 & 42.72667 & 29.7 & 44 & $21: 11$ & ON & OF \\
\hline 50 & 29921 & 42.05 & 29.7 & 43 & $21: 12$ & ON & OF \\
\hline 51 & 30.123 & 41.685 & 29.9 & 43 & 21.13 & ON & $O N$ \\
\hline 52 & 30.1134 & 41.44333 & 29.9 & 43 & $21: 14$ & $O N$ & $O N$ \\
\hline 53 & 30.0236 & 41.37333 & 29.8 & 43 & $21: 15$ & ON & ON \\
\hline 54 & 30.0132 & 41.29833 & 29.8 & 43 & $21: 16$ & $\mathrm{ON}$ & $O N$ \\
\hline 55 & 29.99657 & 41.23333 & 29.8 & 42 & $21: 17$ & ON & OFF \\
\hline 56 & 2959543 & 4119667 & 29.7 & 42 & $21 \cdot 18$ & ON & OF \\
\hline 57 & 29.63333 & 4111833 & 294 & 42 & $21 \cdot 19$ & ON & OF \\
\hline 58 & 29.46333 & 41.1 & 29.3 & 42 & $21: 20$ & ON & OFF \\
\hline 59 & 29.44657 & 41.1 & 29.2 & 42 & $21: 21$ & $O N$ & OFF \\
\hline 60 & 29.3 & 41.01667 & 29.1 & 42 & $21: 22$ & ON & OFF \\
\hline
\end{tabular}

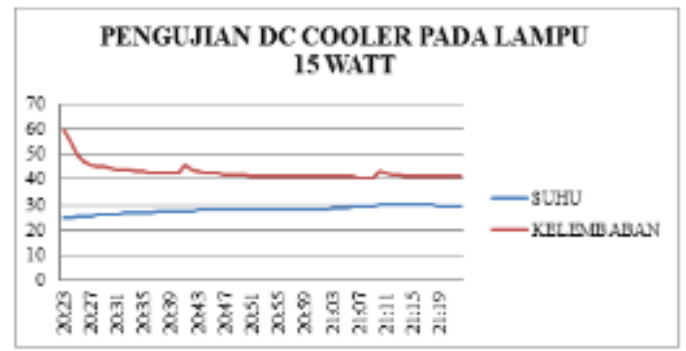

Gambar 16 Pengujian dc cooler pada lampu 5 watt.

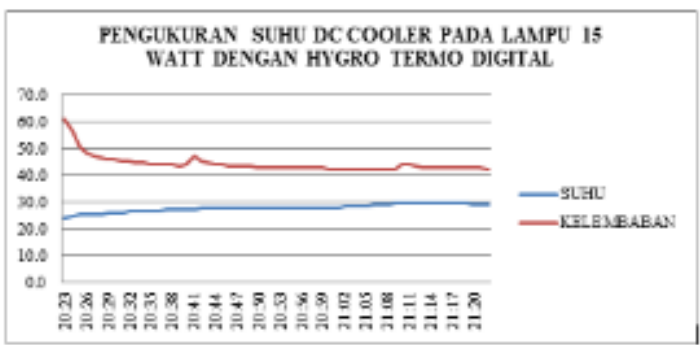

Gambar 17 Pengukuran suhu dc cooler pada lampu 15 watt.

Menurut tabel diatas dalam pengujian Dc cooler dengan menggunakan Lampu 15 watt suhu yang dibaca berada pada suhu dengan rata rata 28.087 ${ }^{\circ} \mathrm{C}$. dan selama 60 menit Dc cooler terus aktif dengan tetap berada dibawah $30^{\circ} \mathrm{C}$. Pengukuran pada lampu 15 watt dengan menggunakan hygro termo digital didapatkan suhu $27,8^{\circ} \mathrm{C}$ seperti pada pengujian saat menggunakan sensor DHT22, tetapi terjadi perbedaan suhu yang relatif kecil. 
RESISTOR (Elektronika Kendali Telekomunikasi Tenaga Listrik Komputer) Vol. 2 No. 2 e-ISSN : 2621-9700, p-ISSN : 2654-2684

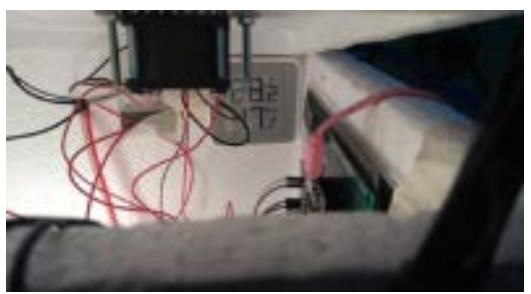

Gambar 18Pengukuran.

- PENGUJIAN SIM800L

Dalam pengujian SIM800l, apabila suhu dalam ruangan mencapai suhu $>30^{\circ} \mathrm{C}$ maka modul SIM800L akan aktif lalu mengirimkan SMS kepada user. Adanya sistem ini diigunakan sebagai pemberitahuan yang tidak menggunakan jaringan internet. Dan mempermudah dalam memberikan tanda bahwa terjadi masalah pada Dc cooler ini. Berikut gambar pengujian SIM800l

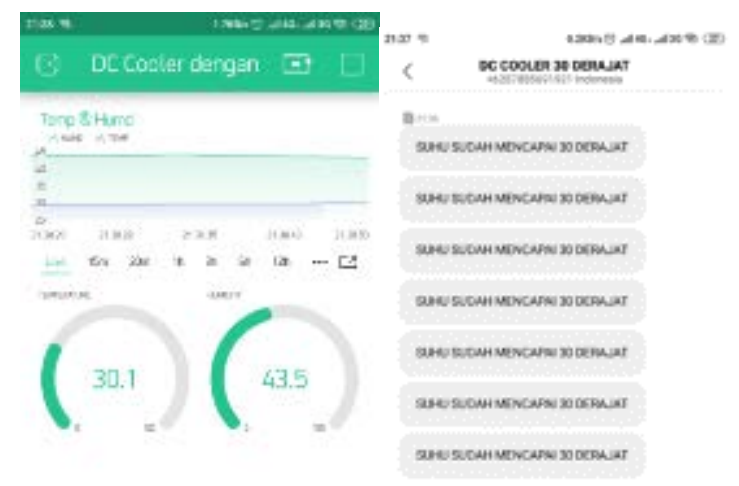

Gambar 19 Tampilam pengujian SIM800L pada Blynk dan SMS.

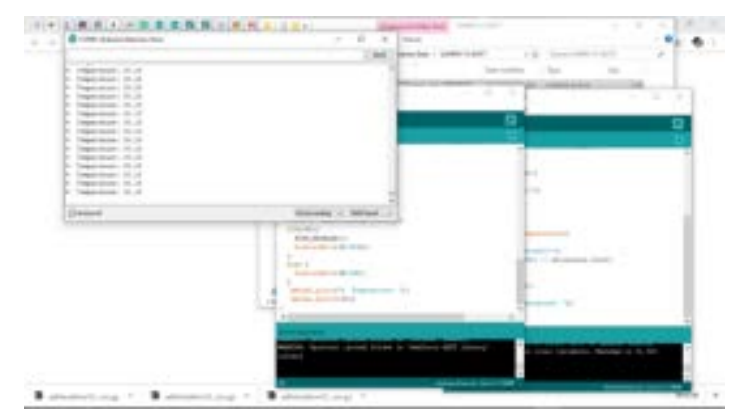

Gambar 20 Tampilan pengujian sim800l pada serial monitor arduino.

Dari tabel diatas menunjukan bahwa pengujian tanpa lampu, dengan lampu 5 watt, dengan lampu 15 watt hasil yang didapat.

Dengan rumus Mean atau rata rata :
Mean $: x=\frac{\sum_{i=1}^{n} x_{i}}{n}$

Dengan :

$x=$ rata rata

$\sum_{i=1}^{n} x_{i}=$ jumlah seluruh nilai data (Suhu)

$n=$ jumlah seluruh frekuensi (Waktu)

Maka hasil yang didapatkan adalah :

Pengukuran dengan menggunakan Sensor DHT22:

Pengujian tanpa lampu : $\frac{1422.859}{60}$

$$
=23,71432{ }^{\circ} \mathrm{C}
$$

Pengujian lampu 5 watt : $\frac{1536.832386}{60}$

$$
=25.6138731^{\circ} \mathrm{C}
$$

Pengujian lampu 15 watt : $\frac{1685.257}{60}$

$$
=28.0876167^{\circ} \mathrm{C}
$$

Pengukuran dengan menggunakan Hygro Termo : Pengujian tanpa lampu : $\frac{1411.1}{60}=23,5^{\circ} \mathrm{C}$

Pengujian lampu 5 watt $: \frac{1473}{60}=25,39{ }^{\circ} \mathrm{C}$

Pengujian lampu 15 watt : $\frac{1673.3}{60}$

$$
=27.9^{\circ} \mathrm{C}
$$

Pengujian ini disebabkan karena pengaruh dari tingginya suhu yang dihasilkan oleh lampu tersebut dan kurangnya kemampuan Dc cooler dalam mendinginkan lampu, sehingga suhu yang dihasilkan berada pada suhu sekitar dibawah $28^{\circ} \mathrm{C}$. Apabila Dc cooler tidak bisa menndinginkan maka ketahanan dari Dc cooler akan cepat rusak. Dari kedua pengukuran diatas terdapat perbedaan suhu sebesar $>0,2^{\circ} \mathrm{C}$ dikarenakan adanya perbedaan akurasi dari sensor DHT22 maupun hygro termo tersebut

\section{KESIMPULAN}

Dari hasil pengujian dan analisa pada prototype yang dibuat, maka didapatkan kesimpulan sebagai berikut: Dalam pengujian ini Dc cooler bahwa alat ini dapat mejaga suhu berada pada $25^{\circ} \mathrm{C}$ saat memakai lampu 5 watt, namun pada lampu 15 watt suhu berada pada sekitar $28^{\circ} \mathrm{C}$, dengan melakukan pengukuran menggunakan alat ukur hygro termo digital sebagai perbandingan terdapat perbedaan suhu sebesar $>0,2^{\circ} \mathrm{C}$. Dalam pengujian SIM800l apabila suhu sudah mencapai $>30^{\circ} \mathrm{C}$ maka sistem akan mengatifkan SIM800L dan buzzer untuk 
RESISTOR (Elektronika Kendali Telekomunikasi Tenaga Listrik Komputer) Vol. 2 No. 2 e-ISSN : 2621-9700, p-ISSN : 2654-2684

memberitahukan bahwa adanya kendala pada Dc cooler ini. Untuk memonitoring suhu dan kelembaban Dc cooler maka harus tetap terhubug pada internet agar aplikasi blynk tetap memonitoring suhu dan kelembaban. Jaringan operator seluler mempengaruhi kinerja alat Dc cooler dikarenakan stabilitas dari sinyal dari jaringan tersebut dan saluran udara mempengaruhi dari alat tersebut.

\section{DAFTAR PUSTAKA}

[1] M. Taştan and H. Gökozan, “An Internet of Things Based Air Conditioning and Lighting Control System for Smart Home,” American Scientific Research Journal for Engineering, Technology, and Sciences (ASRJETS), vol. 50, no. 1, pp. 181-189, 2018.

[2] B. Bohora, S. Maharjan, and B. R. Shrestha, "IoT Based Smart Home Using Blynk Framework," Zerone Scholar, vol. 1, no. 1, pp. 26-30, 2016.

[3] A. Junaidi, "Internet of Things, Sejarah, Teknologi dan Penerapannya,” Jurnal Ilmiah Teknologi Informasi Terapan, vol. 1, no. 3, 2015.

[4] A. Kadir, "Panduan Praktis Mempelajari aplikasi mikrokontroler dan pemrogramannya menggunakan Arduino," Yogyakarta: Andi, 2013.

[5] H. Isyanto and M. Syahrullah, "Perancangan Security Home (Keamanan pada Rumah) Menggunakan Mikrokontroller Berbasis SMS (Short Message Service)," RESISTOR (elektRonika kEndali telekomunikaSI tenaga liSTrik kOmputeR), vol. 1, no. 2, pp. 85-96, 2018.

[6] S. Sriyono and B. Budiyanto, "Studi Penggunaan DC Nanogrid dengan Sumber Photovoltaic pada Beban Bertegangan dibawah Dua Puluh Empat Volt," RESISTOR (elektRonika kEndali telekomunikaSI tenaga liSTrik kOmputeR), vol. 2, no. 1, pp. 1-6, 2019.

[7] M. H. Widianto, "Pengaplikasian Sensor Hujan dan LDR untuk Lampu Mobil Otomatis Berbasis Arduino Uno," RESISTOR (elektRonika kEndali telekomunikaSI tenaga liSTrik kOmputeR), vol. 1, no. 2, 2018.

[8] F. Fadliondi and A. Asriyadi, "Eksperimen dan Simulasi Rangkaian Band Pass Filter (BPF) dengan Resistor dan Kapasitor," RESISTOR (elektRonika kEndali telekomunikaSI tenaga
liSTrik kOmputeR), vol. 1, no. 2, pp. 69-78, 2018.

[9] L. Halim and C. F. Naa, "Desain Sistem Pendayaan Energi Listrik pada Rumah Kaca Pintar dengan Menggunakan Pembangkit Listrik Tenaga Surya,” RESISTOR (elektRonika kEndali telekomunikaSI tenaga liSTrik kOmputeR), vol. 2, no. 1, pp. 43-50, 2019.

[10] F. Fadliondi, M. Kunta Biddinika, and S. I. Omi, "The Humidity Dependence of Pentacene Organic Metal-Oxide-Semiconductor FieldEffect Transistor.,” Telkomnika, vol. 15, no. 2, 2017.

[11] H. Muchtar and R. Apriadi, "Implementasi Pengenalan Wajah Pada Sistem Penguncian Rumah Dengan Metode Template Matching Menggunakan Open Source Computer Vision Library (Opencv)," RESISTOR (elektRonika kEndali telekomunikaSI tenaga liSTrik kOmputeR), vol. 2, no. 1, pp. 39-42, 2019.

[12] R. Samsinar, N. Purnomo, and D. Almanda, "Studi Kelayakan Core Iron Stator Dengan Metode Loop/ELCID Test,” RESISTOR (elektRonika kEndali telekomunikaSI tenaga liSTrik kOmputeR), vol. 1, no. 2, pp. 103-116, 2018.

[13] D. Almanda and D. Bhaskara, "Studi Pemilihan Sistem Pendingin pada Panel Surya Menggunakan Water Cooler, Air Mineral dan Air Laut,” RESISTOR (elektRonika kEndali telekomunikaSI tenaga liSTrik kOmputeR), vol. 1, no. 2, pp. 43-52, 2018.

[14] R. Samsinar and W. Wiyono, "Studi Keandalan Rekonfigurasi Jaringan Program Zero Down Time (Zdt) di Kawasan Sudirman Central Business Distric (Scbd) Menggunakan Software ETAP 12.6,” RESISTOR (elektRonika kEndali telekomunikaSI tenaga liSTrik kOmputeR), vol. 2, no. 1, pp. 65-72, 2019.

[15] F. Fadliondi and B. Budiyanto, "Transistor Efek Medan Berbasis Semikonduktor Organik Pentacene untuk Sensor Kelembaban,” Jurnal Nasional Teknik Elektro dan Teknologi Informasi, vol. 6, no. 2, pp. 204-209, 2017.

[16] D. Almanda and N. Majid, "Studi Analisa Penyebab Kerusakan Kapasitor Bank Sub Station Welding di PT. Astra Daihatsu Motor,” RESISTOR (elektRonika kEndali telekomunikaSI tenaga liSTrik kOmputeR), vol. 2, no. 1, pp. 7-14, 2019. 
RESISTOR (Elektronika Kendali Telekomunikasi Tenaga Listrik Komputer) Vol. 2 No. 2 e-ISSN : 2621-9700, p-ISSN : 2654-2684

[17] E. B. Prasetya, “Aplikasi Manajemen Proyek Konstruksi dengan Metode Critical Path dan Earned Value Management,” RESISTOR (elektRonika kEndali telekomunikaSI tenaga liSTrik kOmputeR), vol. 1, no. 2, pp. 53-68, 2018.

[18] M. H. Widianto, "Alat Pengatur Suhu Otomatis pada Ruangan Produksi Textile Spining Berbasis Mikrokontroler Atmega32 di PT. San Star Manunggal," RESISTOR (elektRonika kEndali telekomunikaSI tenaga liSTrik kOmputeR), vol. 2, no. 1, pp. 51-58, 2019.

[19] P. G. Chamdareno, E. Nuryanto, and E. Dermawan, "Perencanaan Sistem Pembangkit Listrik Hybrid (Panel Surya dan Diesel Generator) pada Kapal KM. Kelud,” RESISTOR (elektRonika kEndali telekomunikaSI tenaga liSTrik kOmputeR), vol. 2, no. 1, pp. 59-64, 2019.

[20] B. Budiyanto and F. Fadliondi, "The Improvement of Solar Cell Output Power Using Cooling and Reflection from Mirror," International Journal of Power Electronics and Drive Systems, vol. 8, no. 3, p. 1320, 2017.

[21] H. Muchtar and R. Sumanjaya, "Control Switch Otomatis pada Tegangan Energi Alternatif dan Tegangan Sumber PLN Menggunakan Raspberry Pi," RESISTOR (elektRonika kEndali telekomunikaSI tenaga liSTrik kOmputeR), vol. 1, no. 2, 2018.

[22] D. Almanda and B. Kusuma, "Audit Energi Listrik Pabrik,” RESISTOR (elektRonika kEndali telekomunikaSI tenaga liSTrik kOmputeR), vol. 1, no. 1, 2018.

[23] F. Fadliondi, N. Hasanah, and A. Asriyadi, "Simulasi dan Pembuatan Rangkaian Penyearah Gelombang Penuh dengan Trafo Center Tapped dengan Memakai Perangkat Lunak LT SPICE,” RESISTOR (elektRonika kEndali telekomunikaSI tenaga liSTrik kOmputeR), vol. 2, no. 1, pp. 23-28, 2019.

[24] P. G. Chamdareno and H. Hilal, "Analisa Pembangkit Listrik Tenaga Hybrid PLTDPLTS di Pulau Tunda Serang Banten,” RESISTOR (elektRonika kEndali telekomunikaSI tenaga liSTrik kOmputeR), vol. 1, no. 1, pp. 35-42, 2018.

[25] M. Collotta and G. Pau, "Bluetooth for Internet of Things: A fuzzy approach to improve power management in smart homes," Computers \&
Electrical Engineering, vol. 44, pp. 137-152, 2015.

[26] S. Sunaryo and U. B. Sudibyo, "Penggunaan Pendingin Thermoelectric pada Bts Indoor untuk Mengurangi Konsumsi Energi Listrik,” Prosiding Semnastek, 2015.

[27] S. Kunjumon, K. Pinto, and J. Saldanha, "Temperature and humidity monitoring and alert management system," International Journal of Engineering Research and General Science, vol. 4, no. 4, pp. 349-351, 2016.

[28] M. Nasution, "Rancang Bangun Dan Analisis Termoelektrik Peltier Cooler Untuk Sistem Pendingin,” 2013. 